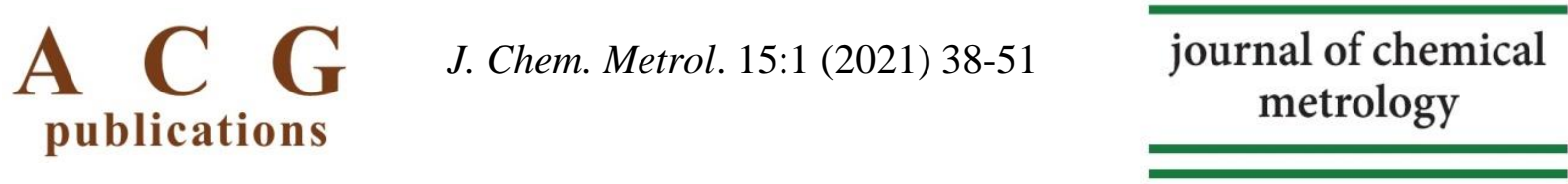

\title{
Measurement uncertainty evaluation for titrimetric determination of benzoic acid purity
}

\author{
Lokman Liv*'P \\ Electrochemistry Laboratory, Chemistry Group, National Metrology Institute of Turkey, \\ (TUBITAK UME), Gebze, Kocaeli, Türkiye
}

(Received November 20, 2020; Revised December 24, 2020; Accepted January 01, 2021)

\begin{abstract}
The uncertainty budget for the determination of benzoic acid purity by potentiometric titrimetry was proposed. For this purpose alcoholic potassium hydroxide solution was standardized with benzoic acid supplied from National Institute of Standards and Technology (NIST) (SRM 39j), then the purity of the benzoic acid sample was determined by the same way. Measurement uncertainty evaluation of the method was exhaustively evaluated according to the EURACHEM/CITAC Guide CG 4, JCGM 100: 2008 and EUROLAB Technical Report No.1/2007, based on the bottom-up approach. Moreover, these results were compared with the results based on the top-down approach according to the EUROLAB Technical Report No.1/2007 and NORDTEST: NT TR 537. The measurement uncertainty was separately evaluated for the factor determination and the purity determination of one and six samples of benzoic acid for the bottom-up approach. The uncertainty sources for the purity determination of benzoic acid were carbon dioxide mole fraction, nominal concentration of benzoic acid, factor of alcoholic potassium hydroxide, amount of titrant consumption, the molar mass of benzoic acid and sample amount, respectively. Among these, the highest contributions to the uncertainty budget were found to be the factor of alcoholic $\mathrm{KOH}$ solution and the amount of titrant consumption for one and six samples, respectively. The expanded uncertainties for one and six measurements based on the bottom-up approach were found as $0.508 \%$ and $0.509 \%$, and the expanded uncertainty for six measurements based on the top-down approach was found as $0.114 \%$.
\end{abstract}

Keywords: Carboxylic acids; carbonyl compounds; electrochemistry; measurement uncertainty; bottom-up approach; top-down approach. (@ 2021 ACG Publications. All rights reserved.

\section{Introduction}

Benzoic acid, the simplest aromatic carboxylic acid, is used in many areas such as a precursor to plasticizers and preservatives, a medicine additive and a standard for bomb calorimeter. Benzoic acid and its salts are used as a preservative in the food industry and as an additive in the pharmaceutical industry. Benzoic acid and its derivatives prevent the reproduction of yeast, mold and some types of bacteria and it is represented by E210 - E213 codes in the food industry. Benzoic acid is also used to cure some skin diseases such as ringworm, tinea athlete's foot. Moreover, it was reported that benzoic acid was used as an analgesic, antiseptic and expectorant in the early of $20^{\text {th }}$ century [1]. Since benzoic acid is widely used as mentioned above, accurate determination of it is very important.

Several methods are available for the determination of benzoic acid purity in literature such as freezing range / specific heat measurements [2], differential scanning calorimeter (DSC) [3], nuclear magnetic resonance spectroscopy (NMR) [4] and potentiometric titrimetry [5, 6]. Among them,

\footnotetext{
*E-Mail: lokman.liv@tubitak.gov.tr
} 
potentiometric titrimetry is widely used in terms of the relatively simple and fast method and requires a cheap instrument. A standard titrimetric method for the purity determination of benzoic acid is available $[5,6]$. Actually, sodium hydroxide is generally used in the standard method. However, potassium hydroxide is used in this study due to its higher solubility in ethanol [7].

Titrimetric purity determination of benzoic acid is based on the acid-base reaction as shown in Figure 1.

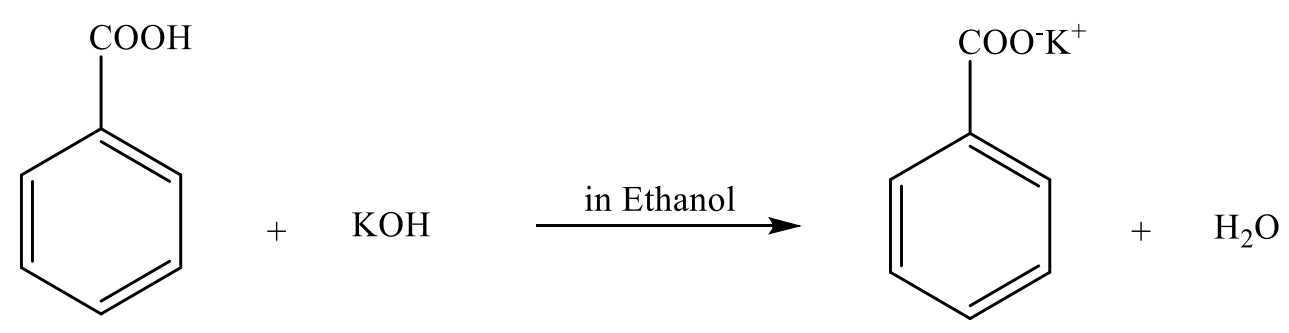

Figure 1. Acid-base reaction between potassium hydroxide and benzoic acid

In the purity determination of benzoic acid with the auto-titration system, the uncertainty sources are classified as the carbon dioxide mole fraction, nominal concentration of benzoic acid, the factor of alcoholic potassium hydroxide, amount of titrant consumption, the molar mass of benzoic acid and sample amount. The similar bottom-up approach was used by EURACHEM and CITAC for strong acid-base titration [8]. In volumetric titrimetry, uncertainties arising from the perception of the color with the naked eye and indicator are estimated to be quite significant. On the other hand, auto-titration system is highly preferred since the inflection point is detected by using the software-assisted auto-titration system containing the automatic dosing unit.

The measurement uncertainty $(U)$ is the quality of the measurement result and accuracy. It provides a half-width interval around the measurement value, in which the true value is inside this halfwidth interval. The uncertainty approaches based on single laboratory measurements are modeling and single-laboratory validation methods. The modeling approach (bottom-up approach) consists of the detailed evaluation for each uncertainty component according to the EURACHEM/CITAC Guide CG 4 [8], JCGM 100: 2008 [9] and EUROLAB Technical Report No.1/2007 [10]. The single-laboratory validation approach (top-down approach) consists of the evaluation of the within-laboratory reproducibility and the bias according to the EUROLAB Technical Report No.1/2007 [10] and NORDTEST Approach [11]. The pros and cons of the modeling approach can be listed as the ability to find and evaluate the index graphs, being seen the detailed effects of each uncertainty component, not requiring extra analysis and danger to underestimate the measurement uncertainty, requiring additional work and deep knowledge, respectively. In a single-laboratory validation approach, there are some advantages such as requiring less work and having realistic measurement uncertainty, and disadvantages such as requiring lots of data, not having index graphs and detailed data for each uncertainty component, respectively $[12,13]$.

This study aimed to evaluate the uncertainty budget of benzoic acid purity determination by potentiometric titrimetry which is known as cheap, simple and accurate technique. To the best of my knowledge, there is no study in the literature regarding the detailed uncertainty evaluations based on the bottom-up (EURACHEM/CITAC Guide CG 4, JCGM 100: 2008 and EUROLAB Technical Report No.1/2007) [8-10] and the top-down (EUROLAB Technical Report No.1/2007 and NORDTEST: NT TR 537) $[10,11]$ approaches and the comparison of these approaches for the purity determination of benzoic acid. The studies using these and similar approaches could be found in literature [14-17]. 


\section{Experimental}

\subsection{Materials and Methods}

Ethanol $\left(\mathrm{C}_{2} \mathrm{H}_{5} \mathrm{OH}, 99.9 \%\right.$, ACS, ISO reagent, $\mathrm{Ph}$. Eur) and potassium hydroxide $(\mathrm{KOH}, 85 \%$, flakes) were obtained from ISOLAB and Carlo Erba, respectively. Benzoic acid standard reference material $\left(\mathrm{C}_{6} \mathrm{H}_{5} \mathrm{CO}_{2} \mathrm{H}, 0.999996 \mathrm{~mol} / \mathrm{mol}\right.$, NIST SRM 39j) was used to standardize the alcoholic $\mathrm{KOH}$ titrant solution. $0.4 \mathrm{~mol} / \mathrm{L}$ tetraethylammonium bromide solution $\left(\mathrm{C}_{8} \mathrm{H}_{20} \mathrm{NBr}\right)$ in ethylene glycol $\left(\left(\mathrm{CH}_{2} \mathrm{OH}\right)_{2}\right)$ was purchased from Metrohm for the storage of the combined measuring electrode.

Metrohm 916 Ti-touch auto-titration system consisting of high accuracy dosing unit, potentiometer, magnetic stirrer, solvotrode easy-clean combined measuring electrode and titrant container was used to perform the purity determination of benzoic acid. Milli-Q Direct 8 water purification system was operated to produce ultrapure water $(18.2 \mathrm{M} \Omega . \mathrm{cm})$. Precisa LS $220 \mathrm{~A}$ analytical balance was used for weighing operations.

\subsection{Preparation of Alcoholic $\mathrm{KOH}$ Solution}

Approximately $5.6 \mathrm{~g}$ of potassium hydroxide was dissolved in $25 \mathrm{~mL}$ carbon dioxide-free ultrapure water, then the volume was completed to $1 \mathrm{~L}$ with ethanol.

\subsection{Measurement Procedure}

Benzoic acid (NIST SRM 39j) was weighed as to be $120 \mathrm{mg}$, then dissolved in $50 \mathrm{~mL}$ ethanol. This solution was titrated with alcoholic potassium hydroxide after stirred for 3 minutes and then the inflection point was automatically calculated. This process was repeated 6 times and the average value obtained was assigned as a factor of the alcoholic $\mathrm{KOH}$ solution and the same procedure was used for the purity determination of benzoic acid samples. Argon gas was passed through the titrant and sample solutions for $30 \mathrm{~min}$ before the measurement to remove the dissolved gases, and passed over the sample solution during the measurement to hinder the gas re-dissolution. The measurements were carried out at $20 \pm 3{ }^{\circ} \mathrm{C}$.

\subsection{Value Assignment and Uncertainty Budget}

The evaluations of the measurement uncertainty for titrimetric determination of benzoic acid were exhaustively performed for the factor, and 1 and 6 samples according to the EURACHEM/CITAC Guide CG 4, JCGM 100: 2008 and EUROLAB Technical Report No.1/2007 [8-10]. The obtained combined uncertainty was multiplied by a coverage factor of 2, corresponding to $95 \%$ confidence level.

The top-down approach, NORDTEST: NT TR 537, also was used for the comparison of the results from the bottom-up approach.

\section{Results and discussion}

\subsection{Standardization of Alcoholic KOH Solution}

Standardization of alcoholic KOH solution was performed according to Eq. (1) [5, 6].

$$
F_{\mathrm{KOH}}=\frac{m_{C R M}}{C \times M \times V}
$$


where $F_{K O H}$ is the factor of alcoholic $\mathrm{KOH}$ solution, $m_{C R M}$ is the amount (mg) of NIST SRM39j, $C$ is the nominal concentration of alcoholic $\mathrm{KOH}$ solution $(0.1 \mathrm{~mol} / \mathrm{L}), M$ is the molar mass of benzoic acid $(122.12081 \mathrm{~g} / \mathrm{mol})$ and $V$ is the titrant consumption $(\mathrm{mL})$. As seen in Eq. (1), $F_{K O H}$ is a dimensionless parameter and the results of repetitive measurements were found in Table 1.

Table 1. Factor results of alcoholic KOH solution

\begin{tabular}{ccc}
\hline Sample & Titrant consumption $(V)$ & Factor result $\left(F_{K O H}\right)$ \\
\hline 1 & 11.00000 & 0.89310 \\
2 & 11.00250 & 0.89235 \\
3 & 11.00490 & 0.89360 \\
4 & 10.99880 & 0.89385 \\
5 & 11.00000 & 0.89282 \\
6 & 11.00250 & 0.89340 \\
\hline$\overline{\mathrm{x}}$ & 11.00144 & 0.89319 \\
\hline $\mathrm{S}_{\mathrm{V}_{\_} \text {rep }}$ and $\mathrm{s}_{\mathrm{F}_{\mathrm{KOH} \_} \text {rep }}$ & 0.00227 & 0.00055 \\
\hline
\end{tabular}

\subsection{Purity Determination of Benzoic Acid Samples}

The purity determination of benzoic acid samples was carried out by Eq. (2) $[5,6]$.

$$
W_{B A}=\frac{K \times F_{K O H} \times V \times C \times M}{m_{\text {sample }}} \times 1000
$$

where $K$ is the unit conversion coefficient $(0.1), m_{\text {sample }}$ is the sample amount and 1000 is the purity conversion coefficient. The purities of benzoic acid samples calculated from six independent measurements were given in Table 2.

Table 2. The purities of benzoic acid samples calculated from six independent measurements

\begin{tabular}{ccc}
\hline Sample & Titrant consumption $(V)$ & Purity result $\left(W_{B A}\right)$ \\
\hline 1 & 11.00000 & 99.98696 \\
2 & 11.00000 & 99.98696 \\
3 & 11.00300 & 100.01423 \\
4 & 10.99800 & 99.96878 \\
5 & 10.99600 & 99.90515 \\
6 & 10.99100 & 100.18693 \\
\hline$\overline{\mathrm{x}}$ & 10.99800 & 100.00817 \\
\hline $\mathrm{s}_{\mathrm{V}_{\_} \text {rep }}$ and $\mathrm{s}_{W_{B A \_} \text {rep }}$ & 0.00415 & 0.09493 \\
\hline
\end{tabular}

\subsection{Value Assignment and Uncertainty Budget}

The mean factor result from Table 1 was used as an assigned value for the factor. The result of sample 5 from Table 2 was used as an assigned value for 1 sample and the average of 6 measurements was used as an assigned value for 6 samples.

The uncertainty budget was formed according to the EURACHEM/CITAC Guide CG 4, JCGM 100: 2008 and EUROLAB Technical Report No.1/2007 [8-10]. Measurement uncertainty budgets were formed and evaluated by accepting the Eq. (1) as a model function for $F_{K O H}$ and Eq. (2) as a model function for $W_{B A}$, respectively. The fishbone diagram for the purity determination of benzoic acid and the factor determination can be seen in Figure 2. 


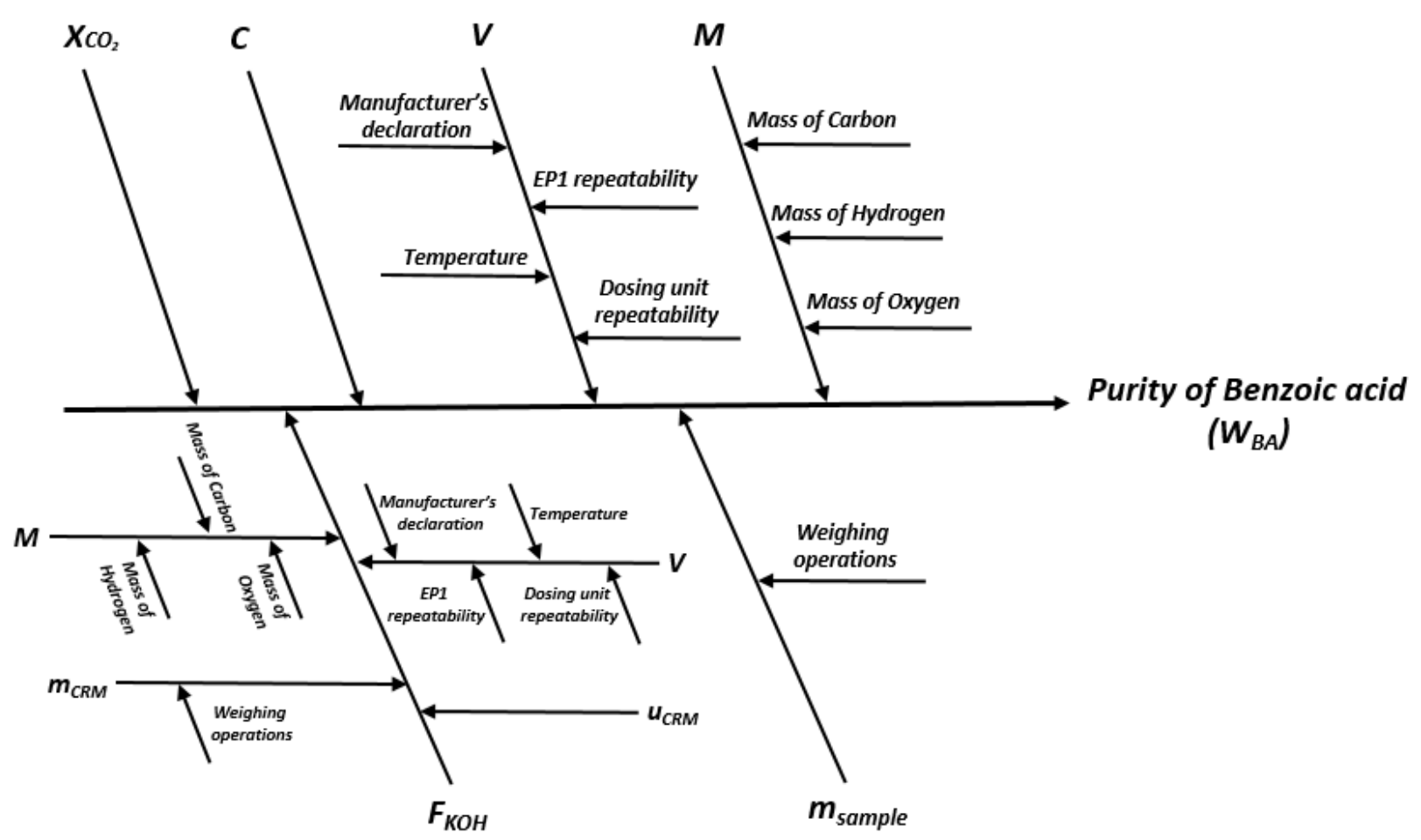

Figure 2. The general fishbone diagram for the purity determination of benzoic acid

Since the uncertainty coming from $F_{K O H}$ involves the uncertainty coming from the concentration of alcoholic $\mathrm{KOH}, C$ has no contribution to the measurement uncertainty for one and six samples. Due to the performing small volume increments, the uncertainty of the potentiometric titration end-point is negligible [18]. Moreover, since argon gas was passed through the titrant and sample solutions before and during the measurement, uncertainty effect of carbon dioxide mole fraction $\left(\mathrm{X}_{\mathrm{CO}_{2}}\right)$ was eliminated. The uncertainty contribution of NIST SRM 39j is also negligible for factor analysis, since the relative standard uncertainty of NIST SRM 39j is at least lower than 70 folds from the relative standard uncertainty of the purity of benzoic acid. However, it was expressed how to evaluate this uncertainty source in order to estimate when this component is important for any analyst.

\subsection{Uncertainty Budget for the Factor of Alcoholic $\mathrm{KOH}$}

The standard uncertainty of $F_{K O H}\left(u_{F}\right)$ consists of 4 different uncertainty sources that are $V, M$, $m_{C R M}$ and $u_{C R M}$ from the factor determination step of alcoholic $\mathrm{KOH}$ solution. The calculation methods of standard uncertainties $(\mathrm{u})$ and sensitivity coefficients (SCs) [10] and related equations are shown in Table 3. 
Table 3. Some equations for the calculation of the uncertainty budget

\begin{tabular}{ccc}
$\begin{array}{c}\text { Uncertainty } \\
\text { source }\end{array}$ & u calculation equation & SC calculation equation* \\
\hline$F_{K O H}$ & $\sqrt{u_{V}^{2}+u_{M}^{2}+u_{m_{C R M}}^{2}+u_{C R M}^{2}}$ & 1 \\
$V$ & $\sqrt{u_{m d}^{2}+u_{\text {temp }}^{2}+u_{\text {du_rep }}^{2}+u_{V-r e p}^{2}}$ & $\frac{K \times F_{K O H} \times C \times M \times 1000}{m_{\text {sample }}}$ \\
$M$ & $\sqrt{\left(7 \times u_{\mathrm{M}_{\mathrm{C}}}\right)^{2}+\left(6 \times u_{\mathrm{M}_{\mathrm{H}}}\right)^{2}+\left(2 \times u_{\mathrm{M}_{\mathrm{O}}}\right)^{2}}$ & $\frac{K \times F_{K O H} \times V \times C \times 1000}{m_{\text {sample }}}$ \\
$m_{\text {sample }}$ & $\sqrt{2 \times\left(U_{\text {balance }} / 2\right)^{2}}$ & $-\frac{K \times F_{K O H} \times V \times C \times M \times 1000}{m_{\text {sample }}{ }^{2}}$ \\
\hline
\end{tabular}

* The sensitivity coefficients (SCs) were calculated by taking the first derivatives of the relevant uncertainty source from the related equations.

The standard uncertainty of $V\left(u_{V}\right)$ includes 4 different uncertainty sources that are manufacturer's declaration, temperature effect, repeatability of dosing unit and repeatability of titrant consumption. Manufacturer's declaration is $\pm 0.017 \mathrm{~mL}$. The standard uncertainty of manufacturer's declaration $\left(u_{m d}\right)$ was calculated by triangular distribution as $0.017 / \sqrt{6}=0.00675 \mathrm{~mL}$. The standard uncertainty of temperature effect $\left(u_{\text {temp }}\right)$ using triangular distribution was calculated by Eq. (3).

$$
u_{t e m p}=V_{D U} \times \gamma \times \Delta t / \sqrt{6}
$$

where $V_{D U}$ is the volume of dosing unit $(20 \mathrm{~mL}), \gamma$ is the thermal expansion coefficient of ethanol $(0.0011$ $\left.{ }^{\circ} \mathrm{C}^{-1}\right)$ and $\Delta t$ is the difference of liquid temperature from $20^{\circ} \mathrm{C}\left(3{ }^{\circ} \mathrm{C}\right)$. Then $u_{\text {temp }}$ was found as 0.02694 $\mathrm{mL}$. The standard uncertainty of dosing unit repeatability $\left(u_{d u_{-} r e p}\right)$ was calculated by dividing the standard deviation of 6 dosing operations with a certain volume of alcoholic $\mathrm{KOH}$ solution $\left(s_{d u_{-} r e p}\right)$ to $\sqrt{6}$ and found as $0.00318 \mathrm{~mL}$. After each $11 \mathrm{~mL}$ dosing process, the solutions were weighed and the actual volumes of the solutions were calculated by dividing these amounts to the approximate density of the solution which is $0.836 \mathrm{~g} / \mathrm{mL}$ at $20{ }^{\circ} \mathrm{C}$. The related quantities were demonstrated in Table 4 . The standard repeatability uncertainty of titrant consumption $\left(u_{V_{-} r e p}\right)$ was calculated by dividing the $s_{V_{-} \text {rep }}$ to $\sqrt{6}$ and found as $0.00092 \mathrm{~mL}$. The final standard uncertainty for $V$ was calculated by using Eq. (4) and found as $0.02797 \mathrm{~mL}$.

$$
u_{V}=\sqrt{u_{m d}^{2}+u_{t e m p}^{2}+u_{d u_{-} r e p}^{2}+u_{V_{-} r e p}^{2}}
$$

The standard uncertainty of the molar mass of benzoic acid $\left(u_{M}\right)$ was calculated according to the IUPAC [19] and CIAAW [20] recommendations. The average mass of each element was found by summing the standard atomic weights and dividing them by 2 . The standard uncertainties of mass $\left(u_{M_{i}}\right)$ were calculated by Eq. (5). $\mathrm{M}_{\mathrm{i}, 1}$ and $\mathrm{M}_{\mathrm{i}, 2}$ are the first and second standard atomic weights of the related element as shown in Table 5 .

$$
u_{M_{i}}=\frac{\left|M_{i, 1}-M_{i, 2}\right|}{2 \sqrt{3}}
$$


The uncertainty contribution of each element was found by multiplying $u_{M_{i}}$ by the stoichiometric coefficient. Afterward, the standard uncertainty of the molar mass of benzoic acid $\left(u_{M}\right)$ was calculated by taking the square root of the sum of squares of each uncertainty contribution as seen in Table 5 and found as $0.00409 \mathrm{~g} / \mathrm{mol}$.

Table 4. The calculation of standard uncertainty of dosing unit repeatability $\left(u_{d u \_r e p}\right)$

\begin{tabular}{ccc}
\hline Dosing volume $(\mathbf{m L})$ & Mass of the dosing volume $(\mathbf{g})$ & The calculated volume $(\mathbf{m L})$ \\
\hline & 9.19650 & 11.00060 \\
11 & 9.20100 & 11.00598 \\
& 9.19530 & 10.99916 \\
& 9.21360 & 11.02105 \\
$\overline{\mathrm{x}}$ & 9.20150 & 11.00658 \\
$\mathrm{~S}_{\text {du_rep }}$ & 9.20320 & 11.00861 \\
& & 11.00700 \\
& & 0.00779 \\
\hline
\end{tabular}

The standard uncertainty of each weighing operation was calculated by $\sqrt{\left(U_{\text {balance }} / 2\right)^{2}}$. Since this process was repeated twice when the sample was tared and weighed, the final standard uncertainty for weighing operation $\left(u_{m_{C R M}}\right)$ was expressed as $\sqrt{2 \times\left(U_{\text {balance }} / 2\right)^{2}}$. $U_{\text {balance }}$ was obtained from the calibration certificate as $0.00047 \mathrm{~g}$ and $u_{m_{C R M}}$ was found as $0.00033 \mathrm{~g}$.

The standard uncertainty $(\mathrm{k}=1)$ of NIST SRM 39j, $u_{C R M}$, is $0.000036 \mathrm{~mol} / \mathrm{mol}$ with a 0.999996 $\mathrm{mol} / \mathrm{mol}$ certified value.

When the obtained standard uncertainty values of $u_{V}, u_{M}, u_{m_{C R M}}$ and $u_{C R M}$ were multiplied by the related SC values, the contributions to the total uncertainty were found in units of factor quantity. Then, the expanded uncertainty of $F_{K O H}\left(U_{F}\right)$ was found by multiplying the square root of the sum of these squares by the factor of coverage and the factor result was obtained as $(0.8932 \pm 0.0045),(k=2$, at $95 \%$ confidence level).

The uncertainty budget of the factor analysis is seen in Table 6 . The percentage contributions of the uncertainty sources to the total standard uncertainty can be seen in Figure 3. It was determined that the biggest uncertainty contribution was due to the uncertainty of the titrant consumption.

\subsection{Uncertainty Budget for the Purity of One Sample}

$F_{K O H}, V, M$ and $m_{\text {sample }}$ are important to evaluate the measurement uncertainty for one sample. $u_{M}, u_{m_{\text {sample }}}$ (same with $u_{m_{C R M}}$ ) and $u_{F}$ values are the same as in "Uncertainty Budget for the Factor of Alcoholic $\mathrm{KOH}$ ", whereas the SCs are different. $u_{V_{-}}$rep had no contribution to the uncertainty budget since there were no repetitive measurements for one sample. Therefore, $u_{V}$ was calculated by using Eq. (4) without the $u_{V_{-}}^{2}$ rep component and found as $0.02795 \mathrm{~mL}$.

When the obtained standard uncertainty values of $u_{F}, u_{V}, u_{M}$ and $u_{m_{\text {sample }}}$ were multiplied by the related SC values, the contributions to the total uncertainty were found in units of analyte quantity. Then, the expanded uncertainty of $W_{B A}\left(U_{\text {purity }}\right)$ was found by multiplying the square root of the sum of these squares by the factor of coverage and the purity result for one sample was obtained as $(99.951 \pm$ $0.508) \%,(k=2$, at $95 \%$ confidence level $)$.

The uncertainty budget of the purity of benzoic acid for one sample is seen in Table 7. The percentage contributions of the uncertainty sources to the total standard uncertainty can be seen in Figure 4. It was determined that the biggest uncertainty contribution was due to the uncertainty of the factor followed by the uncertainty of the titrant consumption. 


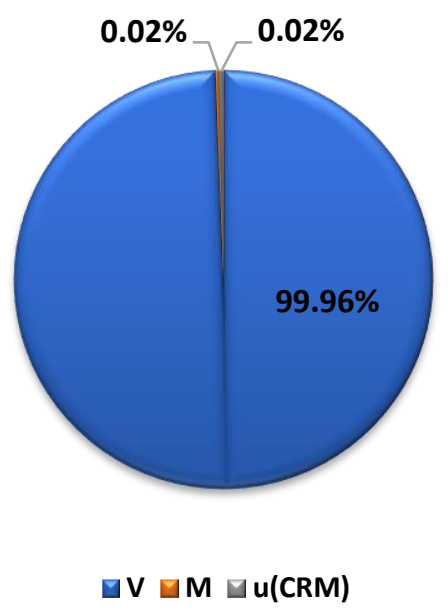

Figure 3. The standard uncertainty contributions for the factor

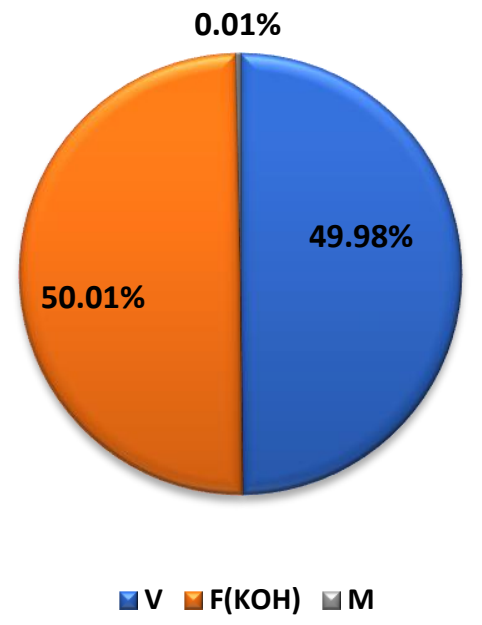

Figure 4. The standard uncertainty contributions for the one sample

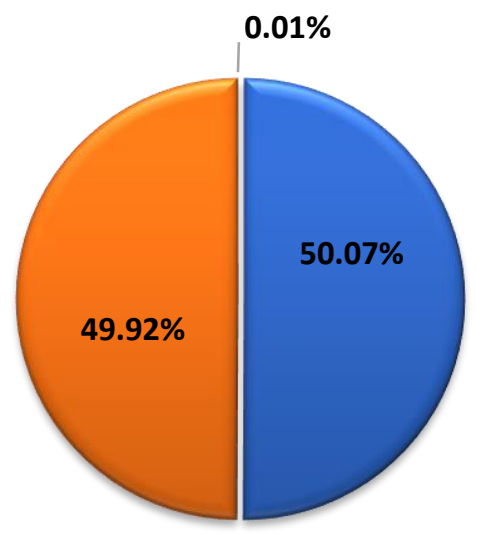

$\square \mathrm{V} \square \mathrm{F}(\mathrm{KOH}) \square \mathrm{M}$

Figure 5. The standard uncertainty contributions for the six samples 


\subsection{Uncertainty Budget for the Purity of Six Samples}

$F_{K O H}, V, M$ and $m_{\text {sample }}$ are important to evaluate the measurement uncertainty for six samples. $u_{M}, u_{m_{\text {sample }}}$ (same with $u_{m_{C R M}}$ ) and $u_{F}$ values are the same for the uncertainty budget of six samples as seen in the previous section, whereas the SCs are different. $u_{V}$ was calculated by using Eq. (4) and found as $0.02801 \mathrm{~mL}$.

When the obtained standard uncertainty values of $u_{F}, u_{V}, u_{M}$ and $u_{m_{\text {sample }}}$ were multiplied by the related SC values, the contributions to the total uncertainty were found in units of analyte quantity. Then, the expanded uncertainty of $W_{B A}\left(U_{\text {purity }}\right)$ was found by multiplying the square root of the sum of these squares by the factor of coverage and the purity result for six samples was obtained as $(100.008 \pm$ $0.509) \%,(k=2$, at $95 \%$ confidence level).

The uncertainty budget of the purity of benzoic acid for six samples is seen in Table 8 . The percentage contributions of the uncertainty sources to the total standard uncertainty can be seen in Figure 5. It was determined that the biggest uncertainty contribution was due to the titrant consumption followed by the uncertainty of the factor.

The uncertainty evaluation based on the top-down approach named the NORDTEST Approach [11] which is similar to the one used in our previous studies [21, 22] was also performed according to Eq. 6.

$$
U_{\text {purity }}=k \sqrt{u\left(R_{w}\right)^{2}+u(\text { bias })^{2}}
$$

$U_{\text {purity }}, u\left(R_{w}\right), u($ bias $)$ and $k$ correspond to the expanded uncertainty of the purity of benzoic acid, standard uncertainties of within-laboratory reproducibility and bias, and the coverage factor as 2 for $95 \%$ confidence level, respectively. $u\left(R_{w}\right)$ was found as the standard deviation of long-term replicates of the NIST SRM 39j, which corresponded to the random error. The random effects were investigated for 73 days $(\mathrm{N}=20)$. It was crucial to indicate that the standardization and sample titrations occurred on different days, $u$ (bias) which was the deviation from the certified reference value and representing the systematic error was calculated by Eq. 7 .

$$
u_{\text {bias }}=\sqrt{R M S_{\text {bias }}^{2}+s_{\text {bias }}^{2} / n+u_{N I S T ~ S R M}^{2}}
$$

where $R M S_{\text {bias }}$ is the average (root mean square) bias, $s_{\text {bias }}$ is the standard deviation of the bias estimates, $n$ is the number of bias estimates and $u_{\text {NIST SRM }}$ is the standard uncertainty ( $\mathrm{k}=1$ ) of NIST SRM 39j. The systematic effects were investigated for 6 days $(\mathrm{N}=6)$ using NIST SRM $39 \mathrm{j}$ and the purity result for benzoic acid samples was found to be $(99.998 \pm 0.114) \%,(k=2$, at $95 \%$ confidence level $)$ and the detailed data was given in Table 9. 
Table 5. The calculation of the standard uncertainty of molar mass of benzoic acid $\left(u_{M}\right)$

\begin{tabular}{|c|c|c|c|c|c|c|}
\hline Component & $\begin{array}{l}\text { Standard atomic weight } \\
\qquad\left(M_{i}\right)\end{array}$ & $\begin{array}{l}\text { Probability } \\
\text { distribution }\end{array}$ & Average mass & $\begin{array}{l}\text { Standard uncertainty } \\
\text { of mass }\left(u_{M_{i}}\right)\end{array}$ & $\begin{array}{c}\text { Stoichiometric } \\
\text { coefficient }\end{array}$ & $\begin{array}{l}\text { Uncertainty } \\
\text { contribution }\end{array}$ \\
\hline $\mathrm{C}$ & {$[12.0096,12.0116]$} & Rectangular & 12.0106 & 0.00058 & 7 & 0.00404 \\
\hline $\mathrm{H}$ & {$[1.00784,1.00811]$} & Rectangular & 1.007975 & 0.000078 & 6 & 0.00047 \\
\hline $\mathrm{O}$ & {$[15.99903,15.99973]$} & Rectangular & 15.99938 & 0.000202 & 2 & 0.00040 \\
\hline $\mathrm{C}_{7} \mathrm{H}_{6} \mathrm{O}_{2}$ & & & 122.12081 & & & 0.00409 \\
\hline
\end{tabular}

Table 6. Uncertainty budget of the factor analysis

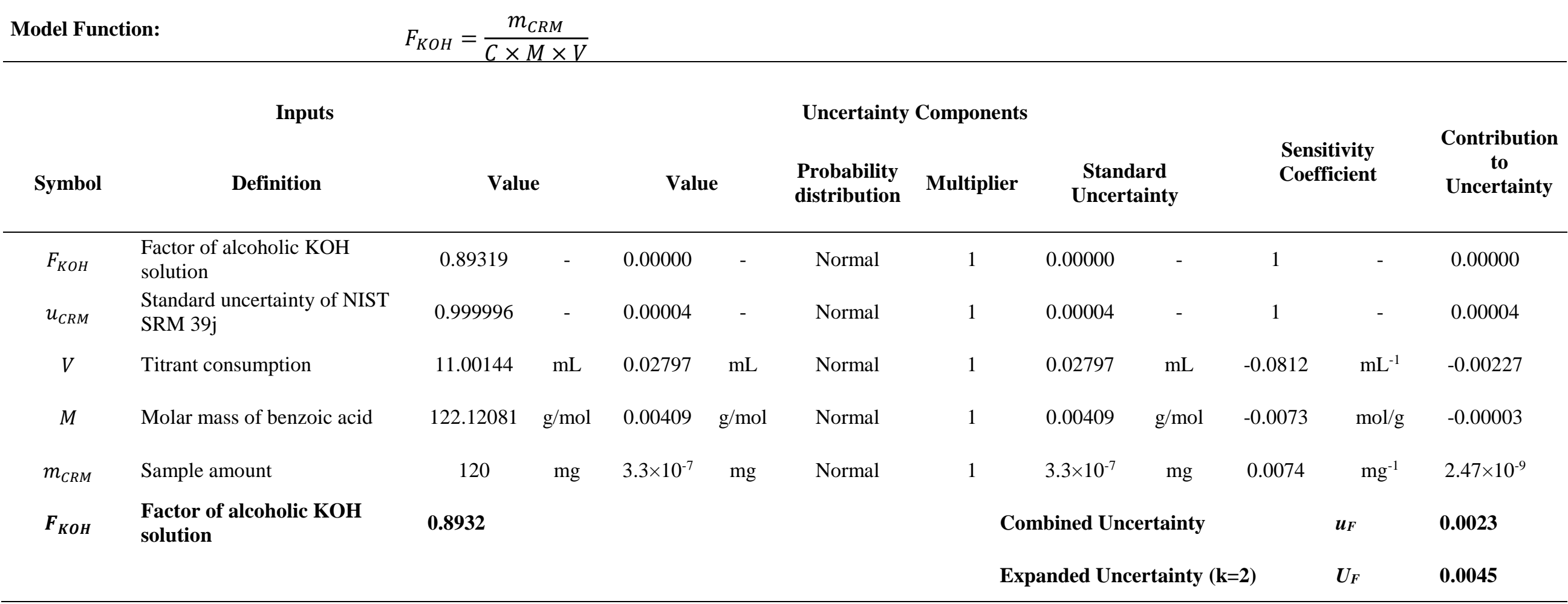


Table 7. Uncertainty budget for the analysis of one sample

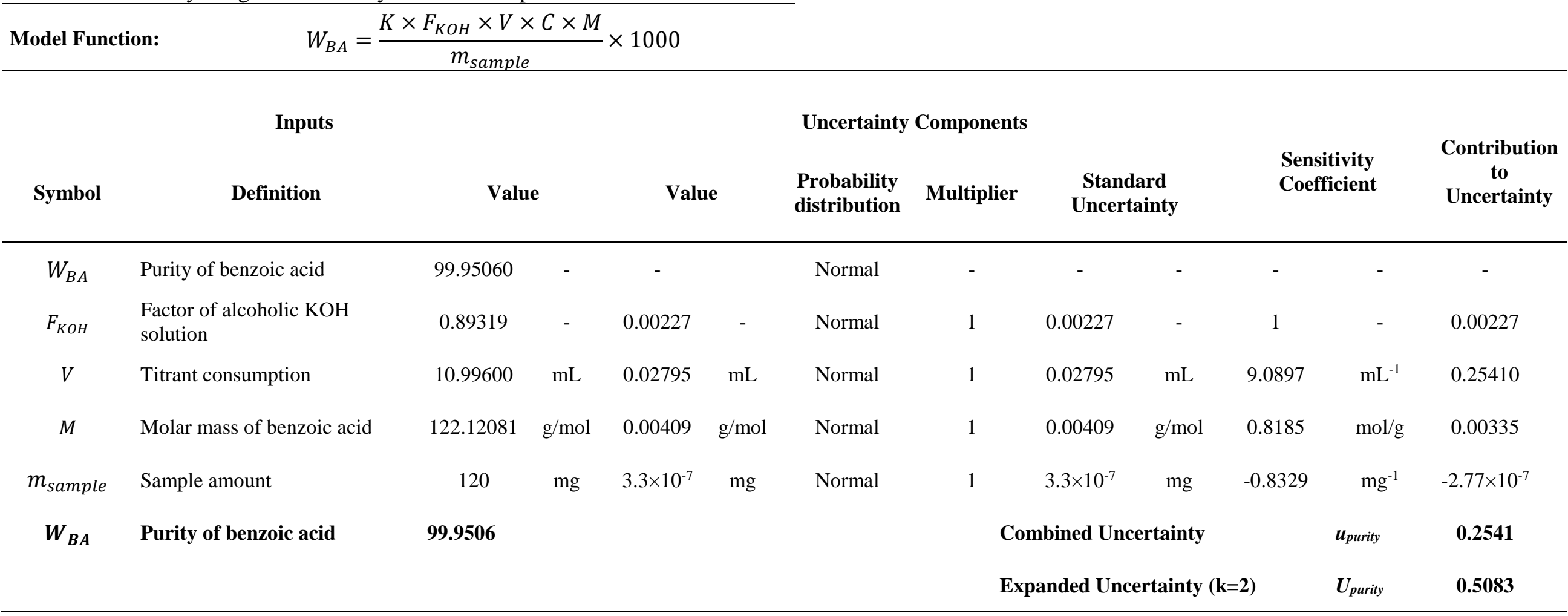


Table 8. Uncertainty budget for the analysis of six samples

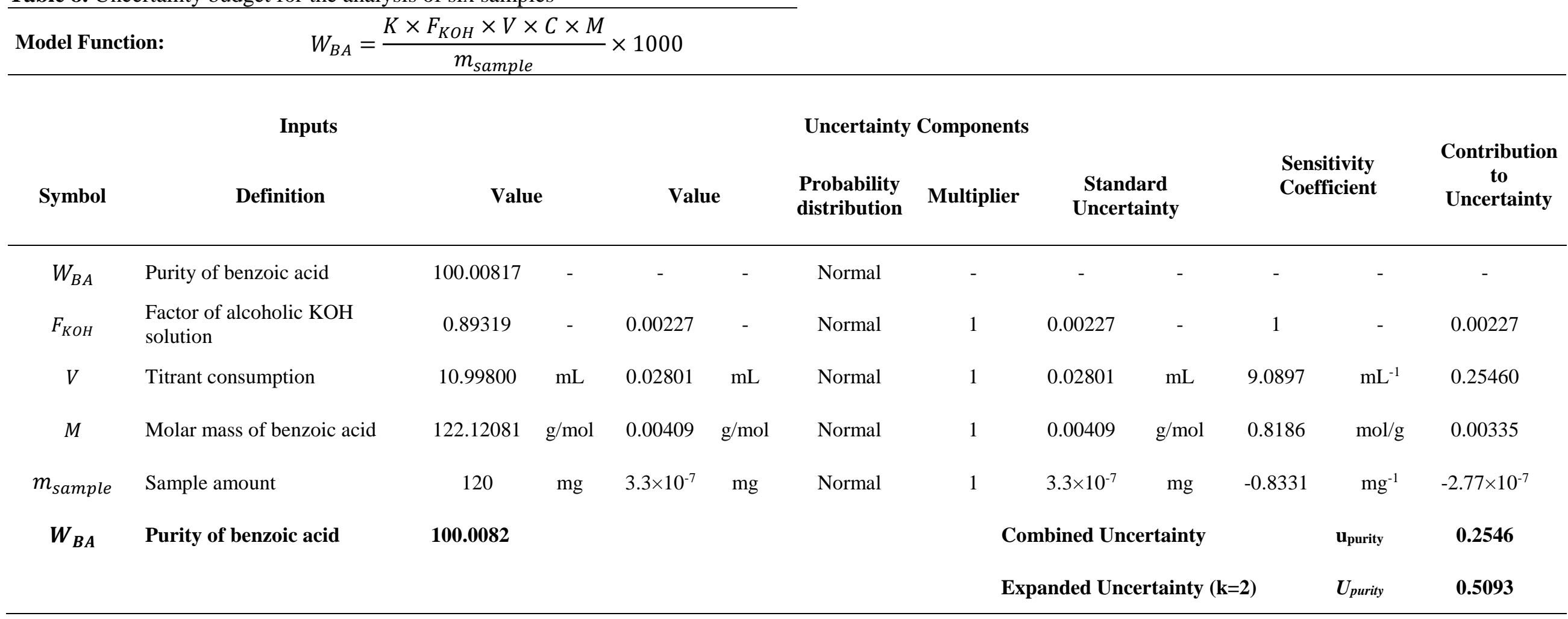


Table 9. The NORDTEST top-down approach parameters

\begin{tabular}{llllllll}
\hline & $\begin{array}{c}\text { Certified } \\
\text { value }\end{array}$ & $\begin{array}{c}\text { Expanded } \\
\text { uncertainty }\end{array}$ & $\begin{array}{c}\text { Combined } \\
\text { uncertainty }\end{array}$ & $\begin{array}{c}\text { Laboratory } \\
\text { result }\end{array}$ & $\begin{array}{c}\text { Combined } \\
\text { relative } \\
\text { uncertainty }\end{array}$ & bias & $\begin{array}{c}\text { Relative } \\
\text { bias }\end{array}$ \\
\hline- & 99.9996 & 0.0072 & 0.0036 & 99.9981 & 0.0036 & -0.0015 & -0.0015 \\
$\left(s_{\text {bias }}^{2} / n\right)_{\text {rel }}$ & 0.0001 & & & & & & \\
$u\left(R_{w, \text { rel }}\right)$ & 0.0569 & & & & & & \\
$u($ bias, rel $)$ & 0.0027 & & & & & & \\
$\boldsymbol{u}_{\text {combined,rel }}$ & $\mathbf{0 . 0 5 7 0}$ & & & & & & \\
$\boldsymbol{U}_{\text {rel }}(\boldsymbol{k}=\mathbf{2})$ & $\mathbf{0 . 1 1 3 9}$ & & & & & & \\
\hline
\end{tabular}

\section{Conclusions}

In this study, bottom-up and top-down uncertainty approaches were separately evaluated and compared with each other. The highest and the lowest uncertainty contributions without counting the sample amount uncertainty based on the bottom-up approach came from the factor of alcoholic $\mathrm{KOH}$ solution and the molar mass of benzoic acid for one sample and the titrant consumption and the molar mass of benzoic acid for six samples, respectively. It was found that the expanded uncertainty values were almost the same for one and six samples.

This is the first detailed and comparative uncertainty evaluation study based on both the bottomup and the top-down approaches for the purity determination of benzoic acid. Although the uncertainty approaches were evaluated according to a particular brand-model titration instrument, both approaches could be successfully applied by users by simply placing the data in their respective equations when using a different titration instrument. When the top-down and the bottom-up uncertainty approaches were compared, the results from the top-down approach had been underestimated. The analysts could use the bottom-up or top-down approach according to the uncertainty estimation in their measurement conditions for the purity determination of benzoic acid by using potentiometric titrimetry. However, if the uncertainty obtained in the top-down approach is within the desired limits, the use of this approach may be preferred since it is based on a simple calculation.

\section{Acknowledgements}

This study was supported by G3GA-E1-06-I project of TUBITAK UME and performed at TUBITAK UME, Electrochemistry Laboratory.

\section{ORCID}

Lokman Liv: 0000-0001-8008-1012

\section{References}

[1] M.G.M.H. Elsayed, A.M. Gomaa and A.E.F.A. Elhassan (2017). Determination of sorbic acid and benzoic acid using reversed phase high performance liquid chromatography (RP-HPLC) in different food commodities, Inventi. Rapid: Pharm. Anal. Qual. Assur. 2017, 22717.

[2] F.W. Schwab and E. Wichers (1940). Preparation of benzoic acid of high purity, J. Res. Nat. Bur. Stand. 25, 747-757.

[3] G.J. Davis and R.S. Porter (1969). Application of the differential scanning calorimeter to purity measurements, J. Therm. Anal. 1, 449-458.

[4] T. Ohtsuki, K. Sato, N. Sugimoto, H. Akiyama and Y. Kawamura (2012). Absolute quantification for benzoic acid in processed foods using quantitative proton nuclear magnetic resonance spectroscopy, Talanta 99, 342-348. 
[5] JSA (1992). Benzoic acid, https://infostore.saiglobal.com/en-us/Standards/JIS-K-8073-1992623155_SAIG_JSA_JSA_1443558/ Accessed 10 March 2020.

[6] JSA (2017). Benzoic acid, https://infostore.saiglobal.com/en-us/Standards/JIS-K-8073-2017623155_SAIG_JSA_JSA_1431433/ Accessed 10 March 2020.

[7] J. O’Neil, P.E. Heckelman, C.B. Koch and K.J. Roman (2007). The merck index: An encyclopedia of chemicals, drugs, and biologicals, J. Am. Chem. Soc. 129, 2197.

[8] JCGM (2008). Evaluation of measurement data - Guide to the expression of uncertainty in measurement, https://www.bipm.org/utils/common/documents/jcgm/JCGM_100_2008_E.pdf Accessed 3 June 2020.

[9] EURACHEM and CITAC (2012). Quantifying uncertainty in analytical measurement, https://www.eurachem.org/index.php/publications/guides/quam\#translations Accessed 27 August 2020.

[10] EUROLAB (2007). Measurement uncertainty revisited: Alternative approaches to uncertainty evaluation (Eurolab Technical Report No.1/2007), https://drive.google.com/file/d/1b_bKTxrJ-a9fYfxxfMqljCrTNnvOXNZ/view Accessed 22 December 2020.

[11] B. Magnusson, T. Näykk, H. Hovind and M. Krysell (2012). Handbook for calculation of measurement uncertainty in environmental laboratories (NT TR 537 - Edition 3.1), http://www.nordtest.info/index.php/technical-reports/item/handbook-for-calculation-of-measurementuncertainty-in-environmental-laboratories-nt-tr-537edition-3.html Accessed 31 May 2020.

[12] I. Leito, L. Jalukse and I. Helm (2014). Estimation of measurement uncertainty in chemical analysis, https://sisu.ut.ee/measurement/uncertainty Accessed 2 June 2020.

[13] I. Leito, L. Jalukse and I. Helm (2015). Using MOOCs for teaching analytical chemistry: Experience at University of Tartu, Anal. Bioanal. Chem. 407, 1277-1281.

[14] I. Leito and I. Helm (2020). Metrology in chemistry: some questions and answers, J. Chem. Metrol. 14, 8387.

[15] D. Dincel, H. Olgan, Z. Canbaloğlu, S. Yalcin, A. Erkuçuk, G. Tırıs and A.C. Gören (2020). Determination of dihydrocapsaicin adulteration in dietary supplements using LC-MS/MS, J. Chem. Metrol. 14, 77-82.

[16] F. Akbas, A. Ozaydin, E. Polat and I. Onaran (2020). Lucilia sericata larval secretions stimulating wound healing effects on rat dermal fibroblast cells, Rec. Nat. Prod. 14, 340-354.

[17] M. Topal (2020). Secondary metabolites of ethanol extracts of pinus sylvestris cones from Eastern Anatolia and their antioxidant, cholinesterase and $\alpha$-glucosidase activities, Rec. Nat. Prod. 14, 129-138.

[18] B. Anes, R.J.N. Bettencourt da Silva, C. Oliveira and M.F. Camões (2018). Uncertainty evaluation of alkalinity measurements on seawater samples, Measurement 129, 395-404.

[19] A.M.H. Van der Veen, J. Meija, A. Possolo and D.B. Hibbert (2016). Guidelines for the use of atomic weights, Chem. Int. 38, 40.

[20] CIAAW, Commission on isotopic abundances and atomic weights (2018). Standard atomic weights, https://www.ciaaw.org/ Accessed 21 Feb 2020.

[21] N. Deniz, L. Liv and N. Nakiboğlu (2017.) Determination and validation method of molybdenum by adsorptive catalytic stripping voltammetry at lead film electrode, J. Chem. Metrol. 11, 46-54.

[22] L. Liv and N. Nakiboğlu (2020). Cost-effective voltammetric determination of boron in dried fruits and nuts using modified electrodes, Food Chem. 311, 126013.

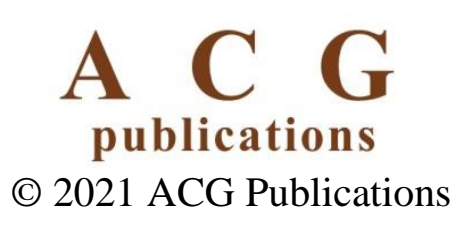

